\title{
A INVESTIGAÇÃO E A CONTAÇÃO DE HISTÓRIA PARA O ENSINO DA LÍNGUA INGLESA NA EDUCAÇÃO INFANTIL
}

\author{
Jaqueline dos Santos Sarmento ${ }^{1}$ \\ Jacqueline Silva da Silva ${ }^{2}$
}

\begin{abstract}
Resumo: Este estudo originou-se de um projeto de pesquisa intitulado "O princípio da Investigação e a Pedagogia Empreendedora”, realizado na Universidade do Vale do Taquari - UNIVATES. Por meio de uma pesquisa de cunho bibliográfico, com enfoque qualitativo, o presente estudo teve como objetivo apresentar a importância da investigaçáo, bem como da contação de história para o ensino de língua inglesa na Educação Infantil. A partir da análise dos materiais bibliográficos coletados, foi possível perceber que a estratégia da investigação, quando utilizada pelo professor com o intuito de ensinar uma nova língua, contribui para estimular às crianças a irem em busca de novas respostas para seus questionamentos não somente em sua língua materna, mas também em outras línguas, como o inglês.
\end{abstract}

Palavras-chave: Educação Infantil. Ensino. Língua Inglesa. Investigação. Contação de história.

\section{THE SCIENCE INQUIRY AND STORYTELLING FOR ENGLISH LANGUAGE TEACHING IN CHILDREN EDUCATION}

\begin{abstract}
This study originated from a research project entitled "The Principle of Research and Entrepreneurial Pedagogy", carried out at the University of Vale do Taquari - UNIVATES. Through bibliographic research, with a qualitative focus, the present study aimed to present the importance of research, as well as of storytelling for the teaching of English in Early Childhood Education. From the analysis of the bibliographic materials collected, it was possible to realize that the investigation strategy, when used by the teacher with the aim of teaching a new language, contributes to stimulating children to go in search of new answers to their questions not only in their native language but also in other languages, such as English.
\end{abstract}

Keywords: Children Education. Teaching. English Language. Scientific inquiry. Storytelling.

1 Graduanda de Letras Português/Inglês e Bolsista de Iniciação Científica da Universidade do Vale do Taquari - Univates, jaqueline.sarmento@universo.univates.br

2 Doutora em Educação, docente do curso de Pedagogia e do Programa de Pós-Graduação em Ensino e Ensino de Ciências Exatas da Universidade do Vale do Taquari - Univates, jacqueh@univates.br 


\section{INTRODUÇÃO}

O presente artigo decorre dos estudos realizados como bolsista de Iniciação Científica na pesquisa "O princípio da Investigação e a Pedagogia Empreendedora", da Universidade do Vale do Taquari - Univates. O objetivo foi aproximar os meus estudos sobre a investigação com o meu Trabalho de Conclusão de Curso, do curso de Letras, que trata sobre o ensino de língua inglesa (doravante LI) para crianças por meio da contação de uma história neste idioma.

Com base nas leituras realizadas dos referenciais teóricos que abordam sobre o tema da investigação, foi possível perceber que se utilizada no ambiente escolar pelo professor como uma estratégia de ensino, pode contribuir para que a criança, por meio do seu próprio interesse, busque estratégias para resolver os problemas que fazem parte do seu cotidiano. Assim, a criança, além de adquirir novos conhecimentos, também estará desenvolvendo o protagonismo infantil.

O ensino de língua inglesa para crianças, por sua vez, está cada vez mais tornando-se pauta entre pesquisadores e professores em relação às metodologias que podem ser utilizadas para o ensino desse idioma. Dentre esses pesquisadores, incluise Sunti (2012) que defende a importância de envolver as crianças em atividades lúdicas para que despertem o interesse em aprender uma nova língua.

Diante disso, nas próximas seçôes serão apresentadas a metodologia, o conceito de investigação e as suas contribuições para o ensino, e, em seguida, o ensino de língua inglesa para crianças e na sequência, a contaçáo de histórias para o ensino deste idioma. Após, será explicitada a importância da investigação e da contação de histórias para o ensino de inglês na Educação Infantil e, por fim, as considerações finais.

\section{METODOLOGIA}

A presente pesquisa seguiu uma abordagem qualitativa de cunho bibliográfico, cuja intenção é apresentar os conceitos sobre investigação e ensino de língua inglesa para crianças da Educação Infantil. A pesquisa bibliográfica, de acordo com Gil (2002, p. 44) "é desenvolvida com base em material já elaborado, constituído principalmente de livros e artigos científicos".

A pesquisa qualitativa, por sua vez, conforme Chemin (2015, p. 56), "trata-se da investigação de valores, atitudes, percepçóes e motivaçóes do público pesquisado, com o objetivo principal de compreendê-los em profundidade". Desse modo, se caracteriza pela busca da compreensão de informações sobre o objeto de estudo.

A coleta dos referenciais teóricos ocorreu entre os meses de abril e dezembro de 2019, por meio da leitura de artigos, livros, e-books relacionados ao projeto e escrita de fichamentos. Dentre os materiais coletados está autores que abordam sobre o ensino de língua inglesa que ressaltam sobre a importância do ensino de LI para crianças tais como, Schlatter e Garcez (2012) e Aquino e Tonelli (2017), além de autores que tratam sobre a investigaçáo, como Baptista (2010), Silva (2011) e Ferraz e Sasseron (2017). 


\section{A investigaçáo como estratégia para a Educaçáo Infantil}

A investigaçáo é compreendida neste estudo como algo essencial na vida das pessoas, "é uma prática cotidiana, uma atitude existencial e ética, necessária à interpretaçáo da complexidade do mundo, dos fenômenos, dos sistemas de convivência" (SILVA, 2011, p. 26). Por meio desta, tanto adultos quanto crianças podem encontrar estratégias para solucionarem problemas que se manifestam no cotidiano.

Ao entendermos isso, rompemos com a falsa crença de que investigação é uma atividade restrita aos laboratórios e aos cientistas, ou então que ela é apenas utilizada para a produção de materiais científicos no meio acadêmico. Isso porque, realizamos atividades investigativas desde a infância, como explorar os objetos ao nosso redor, até a vida adulta, como por exemplo, no momento em que comparamos preços de produtos em mercados (SILVA; BEUREN; LORENZON, 2016).

A investigação quando utilizada no espaço escolar, pelo professor, como uma estratégia de ensino para e com as crianças $^{3}$, pode contribuir para o desenvolvimento da autonomia, da criatividade e do senso crítico delas. Uma vez que, ao se engajarem em uma pesquisa, elas teráo a oportunidade de "discutir em grupo, investigar, observar, registrar, interpretar, tirar conclusóes, prever, argumentar, recolher evidências e resolver problemas" (BAPTISTA, 2010, p. 87). A partir disso, as crianças não só participam da construção das suas aprendizagens como também, cria-se um espaço para que elas e o professor possam aprender coletivamente.

Ao encontro dessa estratégia de ensino, o planejamento do professor na perspectiva do Enfoque Emergente possibilita que ele tenha uma escuta atenta sobre aquilo que as crianças manifestam interesse, sob a forma como estas veem e interpretam o mundo. Dentro desta perspectiva de planejamento se destaca o protagonismo infantil, no qual se apresenta "especialmente, na concepção de que a criança é um sujeito detentor de inúmeras capacidades, sendo reconhecida como capaz de encontrar suas próprias soluçóes para problemas cotidianos" (SILVA; BEUREN; LORENZON, 2016, p. 14). Assim, essa estratégia que envolve a elaboração de projetos de investigação permite não só que a criança desenvolva sua criticidade em relaçáo ao que vivencia no mundo, como também a reconhece como um ser singular que possui curiosidades e tem interesse em aprender coisas novas.

Nesse sentido, é preciso destacar que o ensino por investigação exige dos professores mudanças em suas práticas pedagógicas, uma vez que o ensino tradicional sofre alteraçóes, pois envolve um trabalho coletivo sem que haja um posicionamento rígido por parte do professor. Cabe ressaltar que, assim como afirma Ferraz e Sasseron $(2017$, p. 4) "este ensino não deve ser pensado como uma estratégia metodológica de ensino específica, mas sim ao modo como o professor possibilita as interaçóes

3 Entende-se que o professor, ao elaborar suas práticas, deve pensar em um ensino para o interesse das crianças e com as crianças, possibilitando que elas também tenham participaçáo na construção de sua aprendizagem. 
entre os alunos e entre estes, os materiais e os conhecimentos". Ou seja, para que o trabalho com a investigação seja realizado é necessário o uso de diferentes estratégias que contribuem para um ambiente de trocas de conhecimento.

Dessa forma, a figura do professor é fundamental para a realização de projetos que envolvem a investigação, pois é por meio dele que as crianças se sentem encorajadas e desafiadas a resolverem seus próprios problemas. Tal como defendem os autores Edwards, Gandini e Forman (2016, p. 93), ao dizerem que "devemos proporcionar às crianças aquele tipo de ambiente que potencialize seus interesses e talentos e que aprofundem seu desenvolvimento na prática e no pensamento". Assim, é necessário que as crianças estejam inseridas em um espaço que dê a elas a oportunidade de buscarem respostas aos seus questionamentos.

Em relaçáo ao "o que investigar?", Silva, Beuren e Lorenzon (2016) argumentam que o professor deve escutar as crianças, verificar o que elas estão expressando por meio dos gestos e palavras, pois é a partir desse olhar e escuta que podem surgir ideias para a criação dos projetos. Visto que, "esta escuta sensível em sala de aula, permite ao professor e às crianças participarem juntas da construção do conhecimento e assumindo compromissos, objetivando uma educação de qualidade" (SILVA; BEUREN; LORENZON, 2016, p. 23). Desse modo, é possível perceber uma mudança no que se refere ao papel do professor, pois esse deixa de ser apenas um transmissor de conhecimentos para se tornar um guia das aprendizagens de seus alunos.

\section{O ensino da língua inglesa na Educaçáo Infantil}

Sabe-se que as crianças têm mais facilidade em aprender um novo idioma, isso porque, por não considerarem uma língua mais fácil ou difícil do que outra, as crianças são capazes de aprender as línguas que forem apresentadas a elas (FRAGOZO, 2018). Além disso, o aprendizado de uma segunda língua ainda na infância, permite que a criança tenha acesso a novos conhecimentos. Uma vez que, é através da língua, das interaçóes que estabelecemos com os outros, seja no grupo familiar, escolar e na comunidade, que contribuem para nosso desenvolvimento humano e social e que nos constitui como sujeitos.

Desse modo, a escola, por ser um desses espaços que frequentamos em um determinado período da nossa vida, tem o papel de apresentar aos seus alunos "modos de representar e compreender o mundo [...] são modos de criar, criticar e agir em conjunto que merecem ser estimulados e compreendidos, até mesmo para questionar a sua pertinência em novos tempos" (SCHLATTER; GARCEZ, 2012, p. 16-17).

Para os mesmos autores, o intuito de ensinar línguas na escola não é para formar cidadáos falantes de língua inglesa que atuarão em espaços onde essa língua é falada, mas sim "interessa formar cidadão apto a participar da vida social e do mundo do conhecimento que acontece também em inglês" (SCHLATTER; GARCEZ, 2012, p. 41). Assim, ensinar uma nova língua para as crianças é dar a 
elas a oportunidade conhecer outras culturas e também, ajudá-las a desenvolverem o respeito pelas diferenças.

Schlatter e Garcez (2012) reforçam que o desenvolvimento das competências, no ambiente escolar, requer "aprendizagens colaborativas que possibilitem ao educando aprender a fazer com o outro, aprender a conhecer e a articular conhecimentos, e aprender a ser protagonista de decisões e açôes" (SCHLATTER; GARCEZ, 2012, p. 24-25). Dessa forma, o ensino de línguas permite ampliar as relaçóes interpessoais tanto dentro da escola quanto fora dela.

No que se refere ao ensino de língua inglesa para crianças, Aquino e Tonelli (2017) apontam que existe uma escassez de materiais. Diante disso, as autoras destacam que o professor deve então, estar em constante reflexão sobre sua prática para que as necessidades das crianças sejam supridas. Além disso, destacam que "no cotidiano da sala de aula, o tratamento didático precisa se aproximar mais da investigação, em função da necessidade de incentivar os educandos a construir o seu saber" (AQUINO; TONELLI, 2017, p. 61). Ou seja, o trabalho com a investigação permite que a criança exerça um papel ativo no seu processo de aprendizagem.

Desse modo, para que as crianças se sintam motivadas a aprender, é necessário que o professor ofereça a elas um espaço divertido e acolhedor por meio de atividades que envolvam a ludicidade. De acordo com Rocha (2015),

O desenvolvimento do aspecto lúdico além de facilitar a aprendizagem, contribui para o desenvolvimento pessoal, social e cultural, colabora para uma boa saúde mental, prepara para um estado interior fértil, contribui com processos de socialização, comunicação, expressão e consequentemente a curiosidade e a construção do conhecimento (ROCHA, 2015, p. 18).

Assim, a criança estará desenvolvendo suas atitudes e ao modo de agir em diferentes situaçóes, que irá contribuir para a vida dela dentro e fora do espaço escolar. Além disso, por meio da lúdico as crianças têm a oportunidade de interagir entre elas e com o professor e assimilar os conhecimentos aprendidos.

Dessa forma, aprender uma segunda língua ainda na infância pode trazer muitas contribuiçóes para a vida da criança, pois quanto mais cedo for o contato com a língua, nesse caso aqui, a inglesa, melhores serão as aprendizagens nos anos posteriores. Uma vez que, como já mencionado, a idade é uma das razóes que influenciam a aprendizagem de uma língua estrangeira.

\section{A contaçáo de histórias infantis para o ensino da língua inglesa}

Como exposto na seção anterior e em consonância com Sunti (2012), a ludicidade se apresenta como ferramenta potente para tornar o ensino da língua inglesa na etapa da Educação Infantil, mais divertido e atrativo para as crianças.

Além de atividades que envolvem música, jogos, dança e dramatização, a contação de histórias também pode servir como aliada neste ensino. Visto que, de acordo com Tonelli (2007), para formar conceitos e significados reais, a criança precisa ter o contato com algo concreto. Assim, por fazerem parte da vida das 
crianças e desenvolverem a imaginação e a criatividade, as histórias infantis podem colaborar de forma significativa para o ensino e o aprendizado de inglês, pois as histórias permitem a visualização da língua dentro de um contexto significativo, o que facilita a aprendizagem do idioma.

Para Tonelli (2007), por conter ilustraçôes, diferentes tamanhos, texturas e cores, os livros despertam a atenção das crianças e podem ser considerados por elas como um brinquedo a ser explorado. Além disso, as onomatopeias ${ }^{4}$ que estão presentes em algumas histórias, possibilitam que as crianças participem da contação, imitando os sons dos animais, objetos e/ou personagens da história.

Para isso, "a escolha da história a ser utilizada é de suma importância, porque precisa priorizar linguagem e tema acessível aos interesses e idades das crianças. A qualidade das histórias também é um fator de grande relevância" (SCAFFARO, 2006, p. 42). Dessa forma, de nada adianta levar para as crianças uma história que seja extensa e que tenha um vocabulário difícil, mas sim, que tenha personagens e enredo que chamem a atenção a fim de envolvê-las do início até o final da contação.

Tonelli e Lima (2013) enfatizam que, além do professor selecionar a história adequada para as crianças, é necessário que ele crie um ambiente aconchegante para que estas consigam visualizar e escutar a história. E, ainda, é preciso envolver as crianças na contação da história por meio de mímicas, objetos, instrumentos, expressóes faciais, alteração da voz e do ritmo. Deste modo, além de estimular a imaginação e curiosidade das crianças, também permitirá que elas compreendam a história e a participem deste momento.

Nesta perspectiva, compreende-se que as histórias infantis podem contribuir significativamente para o ensino da língua inglesa na Educação Infantil. As crianças, ao ouvirem a história, têm a oportunidade de aprender não só o vocabulário da língua, mas também desenvolver a imaginação e a fantasia.

\section{A investigaçáo e o ensino de língua inglesa para crianças}

Diante do que foi apresentado nas seçôes anteriores, buscou-se mostrar o quanto é importante o trabalho investigativo no ambiente escolar. Esta estratégia de ensino se apresenta como uma forma potente para estimular a curiosidade, desenvolver o senso crítico e a autonomia das crianças para buscarem respostas aos problemas que emergem seu cotidiano.

A estratégia da investigação quando utilizada na escola para o ensino de língua inglesa, pode contribuir para facilitar o aprendizado da língua, pois permite que as crianças se sintam instigadas e motivadas em aprender. Ademais, ao investigar elas descobrem que há outras línguas sendo faladas ao redor do mundo, como o inglês por exemplo que se difere da nossa língua materna, e que cada uma delas têm um vocabulário específico e algo novo para descobrir.

4 Onomatopeias são figuras de linguagem que reproduzem sons por meio de um fonema ou uma palavra, como, por exemplo: toc toc, atchim, buá, nhac, entre outras. 
Assim, a investigação aliada ao ensino de inglês para crianças possibilita que as elas encontrem, por meio dessa língua, novas respostas às suas perguntas. Uma das formas que o professor da Educação Infantil pode utilizar para aguçar o interesse pelo aprendizado desse novo idioma, como já mencionado anteriormente, é a partir de uma contação de história em língua inglesa.

Um exemplo do ensino por meio da língua inglesa e da investigação pode ser evidenciado na história The very hungry caterpillar (Uma lagarta muito comilona) de Eric Carle. A obra conta a história de uma lagarta que cada dia come uma fruta diferente sendo que, a quantidade vai aumentando ao longo de uma semana até ela transformar-se em uma borboleta. Pelo fato da narrativa ser sobre um animal, um tema que perpassa o cotidiano da vida das crianças, contribui para estimular o interesse delas. A partir dessa história, a criança pode aprender, de forma lúdica, os dias da semana, números de 1 a 5 e as frutas em inglês.

A investigação, por sua vez, entra no sentido das crianças se questionarem onde a lagarta vive, o que ela come, como acontece a metamorfose de uma borboleta (as crianças podem, inclusive, visualizar como tal processo ocorre na prática) e ao investigarem essas ou outras perguntas que despertam seus interesses, elas não só aprendem uma nova língua como também têm a oportunidade de investigar aspectos dessa transformação que chamam atenção.

\section{CONSIDERAÇÓES FINAIS}

A partir deste estudo bibliográfico foi possível perceber que a contação de histórias juntamente com a estratégia da investigação, pode contribuir para o ensino da língua inglesa na Educação Infantil. Além disto, permite que as crianças se tornem mais questionadoras, criativas, protagonistas de suas vidas e que possam interagir no ambiente na qual estâo inseridas.

Por meio desta pesquisa também constatou-se que as histórias infantis podem ser utilizadas como um instrumento didático no ensino de LI para crianças. Porém, é preciso enfatizar que este material só será significativo para as crianças, se o professor o selecionar de acordo com o nível da turma e com uma finalidade.

Diante do que foi exposto, percebeu-se que existe uma preocupação no que se refere à formação das crianças, tanto por parte dos autores que defendem a importância do ensino da estratégia da investigaçáo quanto dos que reforçam o ensino de língua inglesa para crianças. Ambos autores reforçam a necessidade de acolher as vozes das crianças, escutar atentamente o que elas têm a dizer e valorizar suas falas. Convém ressaltar o quanto é relevante ofertar um ambiente que seja estimulador e prazeroso às crianças para que possam adquirir conhecimentos.

Dessa maneira, o trabalho com a investigação e o ensino de língua inglesa por meio da contação de história possibilita às crianças o acesso a diferentes conhecimentos, que também podem estar em língua inglesa. Além disso, as capacidades que são desenvolvidas ao longo do trabalho com projetos de investigação auxiliam na formação da criança. 
Por fim, entende-se que o professor tem um papel muito importante neste ensino porque ele será responsável por promover atividades que contribuem para a formação das crianças e para que elas possam se sentir entusiasmadas a aprender. Para tanto, é fundamental que este profissional busque conhecer teorias que estejam de acordo com a faixa etária de sua turma, pois é relevante que se leve em consideração as cem linguagens das crianças

\section{REFERÊNCIAS}

AQUINO, Aline Loyola de; TONELLI, Juliana Reichert Assunção. Ensino de língua inglesa para crianças: um olhar sobre o desenvolvimento de atividades. REVELLI, v. $9 \mathrm{n}$. 4., Dezembro/2017, p. 58-76.

BAPTISTA, M. L. M. Concepçáo e implementaçáo de actividades de investigaçáo: um estudo com professores de física e química do ensino básico. 2010. 561 p. Tese de doutoramento, Educaçăo (Didáctica das Ciências), 2010, Universidade de Lisboa, Instituto de Educação. Disponível em: <https://repositorio.ul.pt/ bitstream/10451/1854/7/Cap.\%204.pdf>. Acesso em: 14 de maio de 2019.

CHEMIN, Beatris Francisca. Manual da Univates para trabalhos acadêmicos: planejamento, elaboração e apresentação. 3. ed. Lajeado: Univates, 2015. E-book. Disponível em: <http://www.univates.br/biblioteca>. Acesso em: 13 de maio de 2019.

EDWARDS, Carolyn; GANDINI, Lella; FORMAN, George. As cem linguagens da criança: a experiência de Reggio Emilia em transformação. Porto Alegre: Penso, 2016, volume 2.

FERRAZ, A. T.; SASSERON, L. H. Espaço Interativo de Argumentaçáo

Colaborativa: condiçóes criadas pelo professor para promover argumentação em aulas investigativas. Ensaio Pesquisa em Educação em Ciência. vol.19, Belo Horizonte, 2017. Disponível em: <http://www.scielo.br/scielo.php?script=sci_arttext\&pid=S1983$21172017000100215 \& \operatorname{lng}=$ pt\&nrm=iso $>$. Acesso em: 29 de ago. de 2019.

FRAGOZO, Carina. Sou péssimo em inglês: tudo o que você precisa saber para alavancar de vez o seu aprendizado. -1 Ed. - Rio de Janeiro: Harper Collins, 2018.

GIL, Antônio Carlos. Como elaborar projetos de pesquisa. 4. ed. São Paulo: Atlas, 2002.

ROCHA, Francisco Rosa da. A ludicidade como método de ensino de língua inglesa. Revista de Educaçáo, Ciência e Tecnologia do IFAM. Vol. 9 - No 2 - Dezembro 2015.

SCAFFARO, Andréa Peixoto. $\mathbf{O}$ uso da atividade de contar histórias como recurso na retenção de vocabulário novo na língua inglesa com crianças na fase pré-escolar. Monografia (Pós-graduaçáo). Universidade do Vale dos Sinos - UNISINOS. São Leopoldo, 2006. 
SCHLATTER, Margarete; GARCEZ, Pedro. Línguas adicionais na escola: aprendizagens colaborativas em Inglês. Erechim: Edelbra, 2012.

SILVA, Jacqueline Silva da. O planejamento no enfoque emergente: uma experiência no $1^{\circ}$ Ano do Ensino Fundamental de Nove Anos. Tese (doutorado). Universidade Federal do Rio Grande do Sul. Faculdade de Educação. Porto Alegre, 2011.

SILVA, Jacqueline Silva da; BEUREN, Jéssica; LORENZON, Mateus. Investigar com crianças: subsídios para a formação e trabalho docente. Lajeado: Ed. da Univates, 2016.

SUNTI, Débora Wanessa Eskelsen de. Língua Inglesa para crianças de 4 e 5 anos de idade. Revista Eventos Pedagógicos v.3, n.1, Número Especial, p. 340 - 349, abr. 2012.

TONELLI, Juliana Reichert Assunção. O uso de histórias infantis no ensino de inglês para crianças: analisando o gênero textual história infantil sob a perspectiva do analisando o gênero textual história infantil sob a perspectiva do interacionismo sócio-discursivo. Maringá, v. 30, n. 1, p. 19-27, 2008.

TONELLI, Juliana Reichert Assunção; LIMA, H. O. Atividade de desenho sobre histórias infantis na aprendizagem de Inglês para crianças. Revista de Ciências Humanas, v. 13, p. 355-375, 2013. 